\title{
Non-adherence of antihypertensive therapy: A serious public health issue in Sri Lanka
}

\author{
Kumanan $\mathbf{T}^{1}$, Guruparan $\mathbf{M}^{2}$, Mohideen $\mathbf{M} \mathbf{R}^{3}$ \\ Journal of the Ceylon College of Physicians, 2016, 47, 50-51
}

\section{Introduction}

Hypertension is the commonest risk factor for the most of the common causes of death in Sri Lanka; coronary heart disease, stroke, heart and renal failure. Nearly one-fifth to one-third of adult Sri Lankans have blood pressure levels that are above normal and the prevalence is comparable to those in the developed countries. ${ }^{1,2,3}$ The problem of hypertension is further compounded by the underuse of effective and generallywell tolerated antihypertensive medications. A large study carried out in the Gampaha district showed that $31.8 \%$ of patients had undetected hypertension and of the diagnosed hypertensives $19.5 \%$ were not on any medications. Only about $32.1 \%$ had optimal blood pressure control. ${ }^{3}$ Among hypertensive patients attending cardiology unit of National Hospital Colombo uncontrolled hypertension was present in $41.1 \%$ of the patients and $19.1 \%$ of them had resistant hypertension. ${ }^{4}$ The data available from the recent yet unpublished studies indicate that sub-optimal blood pressure control is a serious public health issue in Sri Lanka. It has been shown that $50 \%$ of individuals discontinue antihypertensive drugs within 6 to 12 months of their initiation. ${ }^{5} \mathrm{~A}$ multicenter observational study of blood pressure control among clinic attendees done in Colombo, Galle and Kandy showed that only $22 \%$ achieved a blood pressure target of less than 140/90 $\mathrm{mmHg}^{6}$

The benefits of adherence to antihypertensive medications and adopting lifestyle changes in reducing cardiovascular complications are well established and substantial. ${ }^{7,8}$ Factors contributing to non-adherence of antihypertensives are numerous. Fear and mis-

\footnotetext{
${ }^{1}$ Department of Medicine, Faculty of Medicine, University of Jaffna, Sri Lanka.

${ }^{2}$ Cardiology Unit, Teaching Hospital, Jaffna, Sri Lanka.

${ }^{3}$ Department of Internal Medicine, International Medical University, BatuPahat, Johor, Malaysia.
}

Corresponding author: KT

E-mail: mtkumanan@yahoo.com conception related to antihypertensive medications, lack of basic knowledge and understanding about hypertension and an unsatisfactory consultation due to inadequate explanation, poor doctor-patient interaction are some of the patient factors. ${ }^{9}$ Newly diagnosed hypertension, young age group, ethanol abuse and depression or other psychiatric comorbidities are also identified as patient factors contributing to non-adherence. ${ }^{10}$ Prescription of complex drug regimens, non-availability of medications, visit to visit change of doctors are also to be considered as important contributory factors. In the context when drugs are considered as safe poisons, the adverse effects of medications also play a pivotal role in poor adherence.

Patients with little or no symptoms as in hypertension are expected to be poorly adherent. Nonadherence is a global health issue and prevents patients enjoying the full benefits of proven medications. The consequence of non-adherence is detrimental to the patient and substantial to the health system of countries like Sri Lanka. As the Sri Lankan population ages and the cost of health care escalates, the health services are under pressure to find ways and means to empower patients to play a key role in the management of their chronic ailments such as hypertension.

Identifying non-adherence accurately is challenging, often not disclosed by patients and inadequately probed by their physicians. This could be suspected when blood pressure is poorly-controlled while on a reasonable treatment regime, poor knowledge and attitudes regarding antihypertensive medication, but may have to be established from measures such a simple pill count, the use of self-reported questionnaires. However some of these questionnaires suffer from low sensitivity and therefore not entirely reliable and need validation for local clinics. More sophisticated methods include blood and urine analysis of antihypertensive drugs at the time of clinic visit but provide estimates on adherence at a point of time only. These methods are very costly and are not widely available to screen the large numbers of hypertensive patients taking a wide variety of antihypertensive medications. While electronic monitoring is considered a sensitive method of detecting pill-taking, it remains a research tool and impractical and too expensive for widespread adoption. ${ }^{11}$ 
The influence of patient's beliefs and attitudes to their illness too are powerful determinants of adherence. It's an important aspect for improving compliance cost effectively in a country like Sri Lanka. The absence of a cure, minor adverse effects of modern treatment, lifelong use despite good blood pressure control and cost-effectiveness of therapy are some of core issues that should be emphasized by the attending physician and primary care doctor. The consultation with the treating physician is viewed as unsatisfactory in most studies because of inadequate time, insufficient explanations given by the doctor and poor doctorpatient interaction. Consultation skills training may have to be strengthened to overcome these challenges during patient encounters, which are often doctorcentered and brief. The availability of long acting formulations and fixed drug combinations at an affordable cost is expected to improve pill taking but as a single measure is insufficient. But availability of such formulations of antihyperternsive medications in Sri Lanka would help to improve compliance. More research is required to identify the major local factors that influence patient behavior, and doctor-patient interaction. Increasing the effectiveness of adherence may have far greater impact than the use of newer therapies in hypertension while saving health care costs and also influencing other chronic disease management.

\section{References}

1. Wijewardene K, Mohideen MR, Mendis S, Fernando DS, Kulathilaka T, Weerasekara D, Uluwita P. Prevalence of hypertension, diabetes and obesity: Baseline findings of a population based survey in four provinces in Sri Lanka. Ceylon Medical Journal 2005; 50(2): 62-70.

2. Katulanda $P$, Ranasinghe $P$, Jayawardena $R$, Constantine GR, Rezvi Sheriff MH, Matthews DR. The prevalence, predictors and associations of hypertension in Sri Lanka: a cross-sectional population based national survey. Clinical and Experimental Hypertension 2014; 36(7): 484-91. doi: 10.3109/10641963.2013.863321. Epub 2014 Jan 16.

3. Kasturiratne A, Pinidiyapathirage MJ, Pathmeswaran A, Kato $\mathrm{N}$, Wickremasinghe AR, de Silva HJ. Epidemiology of hypertension in an urban population of Sri Lanka. Ceylon Medical Journal 2011; 56(Supplement 1): 60.

4. Kumara WAN, Perera T, Dissanayake M, Ranasinghe P, Constantine GR. Prevalence and risk factors for resistant hypertension among hypertensive patients from a developing country. BMC Research Notes 2013; 6: 373.

5. Burnier M. Medication adherence and persistence as the cornerstone of effective antihypertensive therapy. American Journal of Hypertension 2006; 19: 1190 -6.

6. Katulanda P, Ekanayake R, Mohideen R, Wijesiriwardhana $B$, Illangasekera $U$. Adequacy of control of hypertension in three Provinces in Sri Lanka, Abstracts, 122nd Annual Scientific Sessions of SLMA, Ceylon Medical Journal 2009; 54 (Suppl 1) 55.

7. Turnbull F, Neal B, Ninomiya T, et al. Effects of different regimens to lower blood pressure on major cardiovascular events in older and younger adults: meta-analysis of randomised trials. British Medical Journal 2008; 336: 1121-3.

8. Rashid P, Leonardi-Be J, Bath P. Blood Pressure Reduction and Secondary Prevention of Stroke and Other Vascular Events: A Systematic Review. Stroke 2003; 34(11): 2741-8. Epub 2003 Oct 23.

9. Jokisalo E, Kumpusalo E, Enlund H, Halonen P, Takala J. Factors related to non-compliance with antihypertensive drug therapy. Journal of Human Hypertension 2002; 16: 577-83. doi:10.1038/sj.jhh.1001448

10. Gascón JJ, Sánchez-Ortuño M, Llor B, Skidmore D, Saturno PJ. Treatment Compliance in Hypertension Study Group. Why hypertensive patients do not comply with the treatment: results from a qualitative study. Family Practice. 2004; 21(2): 125-30.

11. Bertholet N, Favrat B, Fallab-Stubi CL, Brunner HR, Burnier M. Why objective monitoring of compliance is important in the management of hypertension. Journal of Clinical Hypertension (Greenwich) 2000; 2: 258-62. 